\title{
Clinical Implications of the Mitotic Index as a Predictive Factor for Malignant Transformation of Atypical Meningiomas
}

\author{
Sae Min Kwon, Jeong Hoon Kim, ${ }^{2}$ Young-Hoon Kim, ${ }^{2}$ Seok Ho Hong, ${ }^{2}$ Young Hyun Cho, ${ }^{2}$ Chang Jin $\mathrm{Kim}^{2}{ }^{2}$ Soo Jeong Nam ${ }^{3}$ \\ Department of Neurosurgery, Dongsan Medical Center, Keimyung University School of Medicine, Daegu, Korea \\ Department of Neurological Surgery, ${ }^{2}$ Asan Medical Center, University of Ulsan College of Medicine, Seoul, Korea \\ Department of Pathology, ${ }^{3}$ Asan Medical Center, University of Ulsan College of Medicine, Seoul, Korea
}

Objective : Intracranial atypical meningiomas have a poor prognosis and high rates of recurrence. Moreover, up to one-third of the recurrences undergo high-grade transformation into malignant meningiomas. We aimed to investigate the clinical factors that can predict the propensity of malignant transformation from atypical to anaplastic meningiomas.

Methods : Between 2001 and 2018, all patients with atypical meningioma, in whom the tumors had undergone malignant transformation to anaplastic meningioma, were included. The patients' medical records documenting the diagnosis of atypical meningioma prior to malignant transformation were reviewed to identify the predictors of transformation. The control group comprised 56 patients with atypical meningiomas who were first diagnosed between January 2017 and December 2018 and had no malignant transformation.

Results : Nine patients in whom the atypical meningiomas underwent malignant transformation were included. The median time interval from diagnosis of atypical meningioma to malignant transformation was 19 months (range, 7-78). The study group showed a significant difference in heterogeneous enhancement ( $77.8 \%$ vs. $33.9 \%)$, bone invasion $(55.6 \%$ vs. $12.5 \%)$, mitotic index (Ml; $14.8 \pm 4.9$ vs. $3.5 \pm 3.9)$, and Ki-67 index (20.7 \pm 13.9 vs. 9.5 \pm 7.1$)$ compared with the control group. In multivariate analysis, increased MI (odds ratio, 1.436; $95 \%$ confidence interval, 1.127-1.900; $p=0.004$ ) was the only significant factor for predicting malignant transformation.

Conclusion : An increased Ml within atypical meningiomas might be used as a predictor of malignant transformation. Tumors at high risk for malignant transformation might require more attentive surveillance and management than other atypical meningiomas.

Key Words : Mitotic index · Atypical meningioma $\cdot$ Malignant transformation.

\section{INTRODUCTION}

Intracranial meningiomas are generally slow-growing, benign tumor, most of which are considered as World Health
Organization (WHO) grade $\mathrm{I}^{13)}$. In contrast, atypical (WHO grade II) or anaplastic meningiomas (WHO grade III) have a significantly poor prognosis, with a high rate of recurrence ${ }^{3,31)}$. Previous reports have documented the recurrence rate of

- Received : May 10, $2021 \cdot$ Revised : July 10, 2021 •Accepted : August 23, 2021

- Address for reprints : Jeong Hoon Kim

Department of Neurological Surgery, Asan Medical Center, University of Ulsan College of Medicine, 88 Olympic-ro 43-gil, Songpa-gu, Seoul 05505, Korea Tel : +82-2-3010-3559, Fax : +82-2-476-6738, E-mail : jhkim1@amc.seoul.kr, ORCID : https://orcid.org/0000-0001-7385-2368 
grade II atypical meningioma to be approximately $23-52 \%$, after surgical resection $^{22,34,49)}$. Moreover, up to one-third of these recurrent tumors undergo high-grade transformation into anaplastic meningiomas ${ }^{4,22,38)}$.

The risk factors for recurrence of atypical meningiomas after surgical resection have been well established in previously published literature ${ }^{25,36,48,49)}$. However, the clinical factors that can predict the transformation of atypical meningiomas into anaplastic meningiomas are not well defined. Among the anaplastic meningiomas, which account for $>85 \%$ of malignant meningiomas, 51-70\% comprise tumors undergoing malignant transformation from lower grades ${ }^{26,32,39,41)}$. Since anaplastic meningiomas, especially transformed anaplastic meningiomas, are associated with more destructive behavior, shorter recurrence intervals, and systemic metastasis compared with atypical meningiomas, predicting the probability of malignant transformation from lower grades is vital for patient management. In this study, we present cases of atypical meningiomas that have undergone malignant transformation and investigate the clinical factors that can predict the propensity for malignant transformation.

\section{MATERIALS AND METHODS}

This study was approved by the Institutional Review Board of Asan Medical Center (AMC IRB 2018-1491). The need for informed consent was waived due to the retrospective nature of the study.

\section{Patient selection}

We retrospectively reviewed 308 consecutive patients diagnosed with atypical meningioma at our hospital between 2001 and 2018. Of these, atypical meningiomas in 11 patients were histopathologically confirmed to have progressed to the anaplastic subtype. The exclusion criteria were as follows : (1) a diagnosis of anaplastic meningioma after resection of atypical meningioma at other locations and (2) a diagnosis of neurofibromatosis type 2 . Of the 11 patients with malignant transformation, two were excluded by exclusion criterion (1). Additionally, three patients who were diagnosed with anaplastic meningioma at our hospital following surgery for atypical meningioma at a different institute were also excluded from the study. Medical records of all included patients document- ing the diagnosis of atypical meningioma prior to malignant transformation were retrieved. When the patient was diagnosed with anaplastic meningioma during the third surgery after undergoing two operations for atypical meningiomas, the clinical data of the second surgery were reviewed.

The control group comprised 56 patients with atypical meningiomas, who were first diagnosed between January 2017 and December 2018 using the 2016 revised WHO criteria. The mean follow-up period was $27.3 \pm 8.1$ months, and none of the tumors in these patients had undergone a malignant transformation.

\section{Radiological and pathological characteristics}

The definitions of radiological and pathological findings were identical to those in our previous study ${ }^{27)}$. Preoperative computed tomography scans and magnetic resonance imaging (MRI) with contrast enhancement were performed in all patients. Tumors were categorized into convexity, falcine, parasagittal, intraventricular, and skull base according to their location. The signal intensity was classified as hypo-/iso-/hyperintense relative to that of the brain cortex. The degree of peritumoral edema was determined from preoperative axial T2-weighted images and classified as mild (smaller than half of the tumor), moderate (greater than half but smaller than the tumor), or severe (greater than the tumor). The shape of the tumor was classified as round or irregular depending on the presence of lobulations at the brain-tumor interface. Bone invasion was defined only when osteolytic lesions were present.

The extent of tumor resection based on the Simpson grade was determined by reviewing the operative note and the 3-month follow-up MRI scans ${ }^{46)}$. Simpson grade 1, 2, or 3 was designated as gross total resection ${ }^{11,12)}$.

The resected specimens of all patients and controls were reviewed histologically and classified according to the 2016 revised WHO classification $^{31)}$. The diagnosis of atypical meningioma was established if it showed one or more of the following characteristics : (1) mitotic count between 4 and 19 per 10 high-power fields (HPF); (2) at least three of the following five histological features : hypercellularity, small-cell change, macronucleoli, sheeting (patternless growth), and spontaneous necrosis; and (3) brain invasion ${ }^{31)}$. Anaplastic meningioma was diagnosed when one of the following was observed : (1) 20 or more mitosis per $10 \mathrm{HPF}$ and (2) evident anaplastic cytology ${ }^{31)}$. The slide review was conducted by neu- 
ropathologists who were blinded to patient information and clinical outcomes.

\section{Postoperative management}

After the diagnosis of atypical meningioma, postoperative MRI studies were obtained at 1 month, 3 months, and then every 6 months thereafter ${ }^{15}$. More frequent follow-up studies were conducted when the patients required more attention. If postoperative radiotherapy was required, it was performed 1 month after the surgery or when recurrence was suspected during the follow-up. The median dose of radiotherapy was $60 \mathrm{~Gy}^{17)}$.

\section{Statistics}

All statistical analyses were performed using R (version 3.3.3; http://www.r-project.org/) and SPSS (version 18.0; SPSS, Chicago, IL, USA). Data are reported as means \pm standard deviations or as percentages. Logistic regression analysis was used to investigate the predictors of malignant transformation. Variables were applied to the multivariate analysis when they exhibited a $p$-value $<0.1$ in the univariate analysis. Associations of each variable were demonstrated with the odds ratio (OR) and a $95 \%$ confidence interval (CI). Statistical significance was set at $p<0.05$. Additionally, to estimate a diagnostically optimal cut-off level for the prediction of transformation, the sensitivity and specificity of the mitotic index (MI) at various levels were calculated, and a receiver operating characteristic (ROC) analysis was performed.

\section{RESULTS}

\section{Patient characteristics}

The demographic and clinical characteristics of the study group with malignant transformation are presented in Table 1 and Fig. 1. Of the nine patients, five were male, and the mean age at the time of diagnosis was $55.4 \pm 10.4$ years. Two patients (case No. 2 and 8) had a previous history of atypical meningioma that had been surgically resected, and one patient (case No. 1) underwent two previous surgeries. The mean tumor size was $54.9 \pm 13.8 \mathrm{~mm}$, and the skull base $(\mathrm{n}=4)$ was the most common location of the tumor. Of the nine patients, eight (88.9\%) showed moderate to severe edema, seven $(77.8 \%)$ had an irregular tumor shape, and seven (77.8\%) had heteroge-

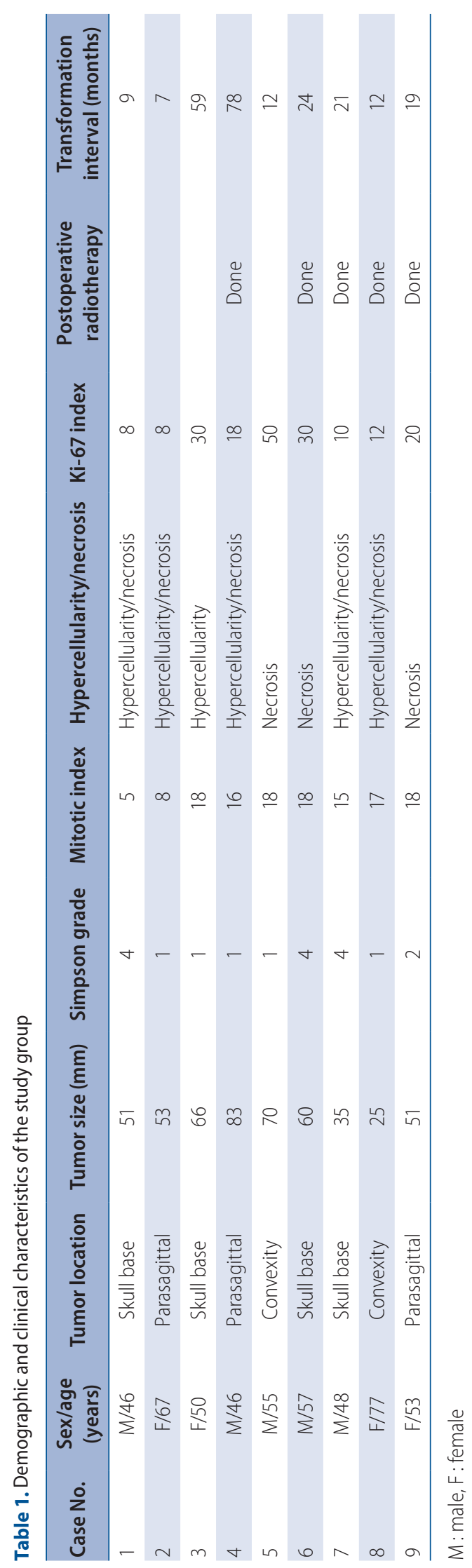


neous contrast enhancement. Bone or sinus involvement was identified in five $(55.6 \%)$ and three $(33.3 \%)$ patients, respectively. The mean MI was $14.8 \pm 4.9$, and seven $(77.8 \%)$ of the nine patients had an $\mathrm{MI} \geq 15$. The mean $\mathrm{Ki}-67$ index was 20.7 \pm 13 .9. The median time interval from diagnosis of atypical meningioma to malignant transformation was 19 months (range, 7-78).

\section{Predictive factor for malignant transformation}

A comparison of the clinical characteristics of the study group and controls is shown in Table 2 and Fig. 2. There were significant associations between heterogeneous enhancement (OR, 6.816; 95\% CI, 1.288-36.062; $p=0.024)$ and bone invasion (OR, 8.750; 95\% CI, 1.885-40.606; $p=0.006)$ and malignant transformation. Compared with the control group, the study group showed a higher proportion of cases with moderate to severe edema and irregular shape; however, the difference was not statistically significant. In terms of histopathological findings, the MI (OR, 1.435; 95\% CI, 1.195-1.723; $p<0.001)$ and Ki67 index (OR, 1.109; 95\% CI, 1.025-1.200; $p=0.010)$ showed significant association with malignant transformation. The rate of postoperative radiotherapy did not differ between the two groups.

In the multivariate analysis, only the MI (OR, 1.436; 95\% CI, $1.127-1.900 ; p=0.004)$ was statistically significant in predicting malignant transformation (Table 3). The ROC analysis showed that the MI had the highest validity at a cut-off value of 8 with a sensitivity of 0.89 and a specificity of 0.86 (Supplementary Fig. 1).

\section{DISCUSSION}

Previously reported studies have shown that $0.16-2.00 \%$ of all meningiomas transform into the high-grade subtype, and among the recurrent meningiomas, $6.3-28.5 \%$ were confirmed to have progressed to a higher grade ${ }^{1,4,21,23,28)}$. Of the atypical meningiomas, 26-33\% showed anaplastic transformation upon histological examination at the time of their recurrence $^{22)}$. Factors related to the malignant transformation of meningiomas have been investigated in several studies, focusing mainly on genetic changes. These studies have suggested the gradual accumulation of genetic changes, including the loss of genetic material from chromosome 22, as the primary

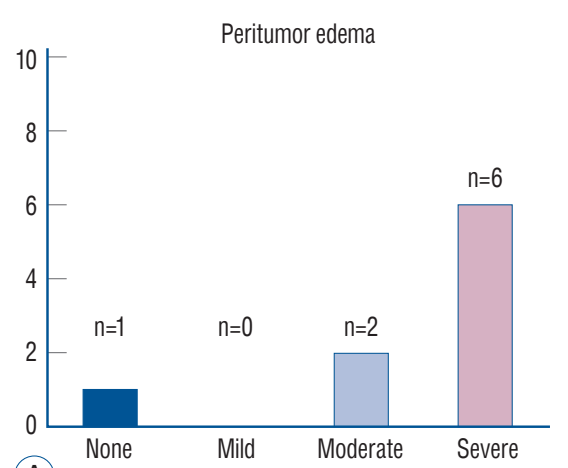

(A)

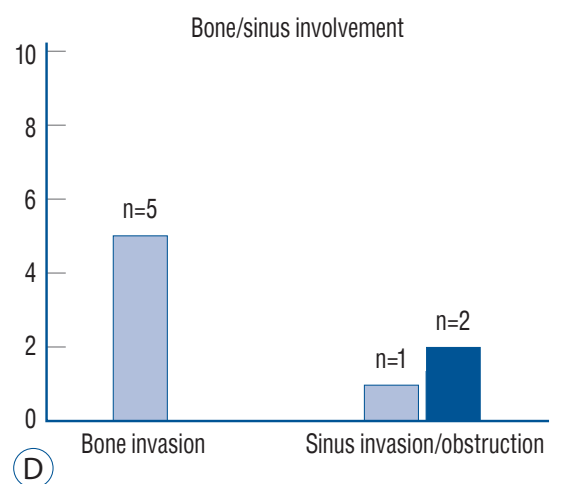

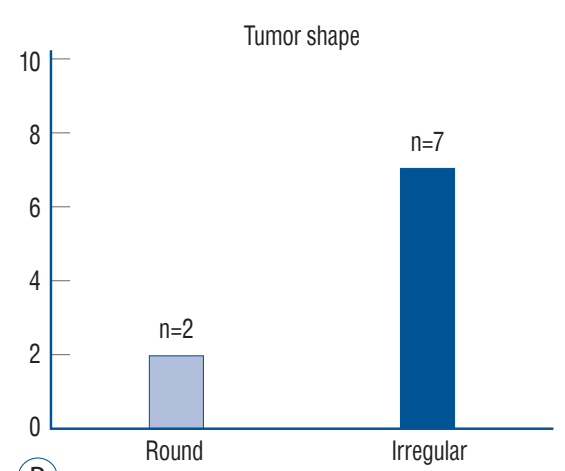

(B)

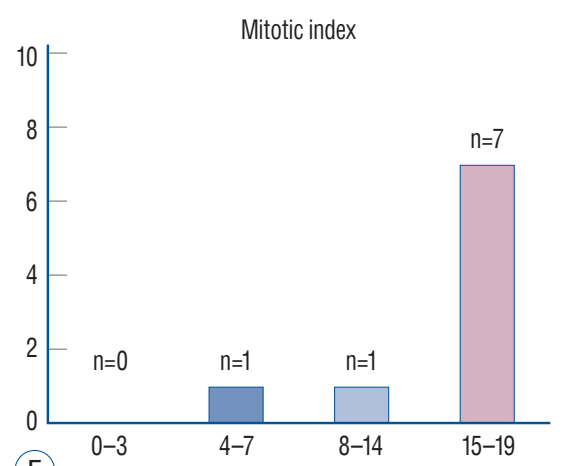

(E)

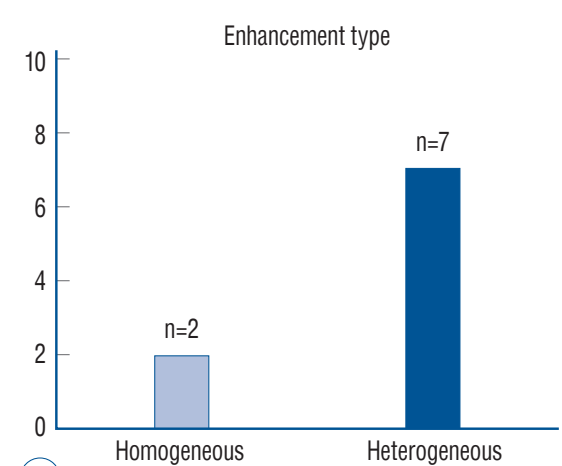

(C)

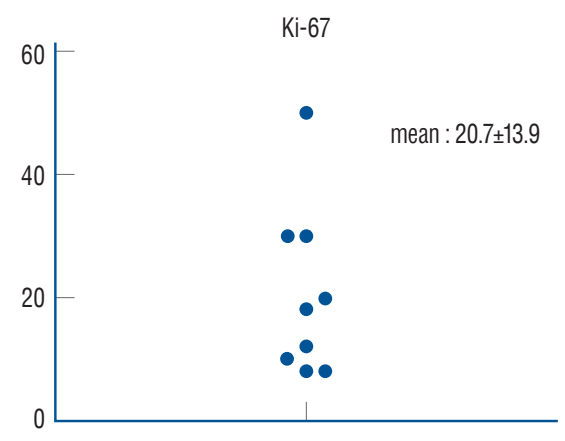

(F)

Fig. 1. A-F : Radiological and histopathological characteristics of the patients. 
event responsible for the transformation of the meningio$\mathrm{ma}^{7,20,28,30,45)}$. However, it is difficult to apply their results in routine clinical practice. Moreover, the clinical factors that favor the malignant progression of atypical meningiomas have not been well identified. In this study, we aimed to identify the feasibility of using routinely available clinical factors for predicting malignant transformation of atypical meningiomas, which might help surgeons in assessing appropriate treatment

Table 2. Comparison of the clinical characteristics between the study group and controls

\begin{tabular}{|c|c|c|c|}
\hline Variable & Study group $(n=9)$ & Controls $(n=56)$ & $p$-value \\
\hline Sex, male & $5(55.6)$ & $25(44.6)$ & 0.554 \\
\hline Age (years) & $55.4 \pm 10.4$ & $57.8 \pm 11.9$ & 0.580 \\
\hline \multicolumn{4}{|l|}{ Tumor location } \\
\hline Convexity & $3(33.3)$ & $23(41.1)$ & \\
\hline Parasagittal/falcine & $3(33.3)$ & $16(28.6)$ & \\
\hline Intraventricular & $0(0.0)$ & $1(1.8)$ & \\
\hline Skull base & $3(33.3)$ & $16(28.6)$ & \\
\hline Tumor size (mm) & $54.9 \pm 13.8$ & $48.1 \pm 10.7$ & 0.123 \\
\hline \multicolumn{4}{|l|}{ Radiological findings } \\
\hline \multicolumn{4}{|l|}{ T2 signal intensity } \\
\hline Hypointensity & $1(11.1)$ & $10(17.9)$ & 0.709 \\
\hline Isointensity & $5(55.6)$ & $23(41.1)$ & 0.517 \\
\hline Hyperintensity & $3(33.3)$ & $23(41.1)$ & 0.827 \\
\hline Moderate to severe edema & $8(88.9)$ & $30(53.6)$ & 0.077 \\
\hline Severe edema & $6(66.7)$ & $19(33.9)$ & 0.074 \\
\hline Irregular shape & $7(77.8)$ & $29(51.8)$ & 0.162 \\
\hline Heterogeneous enhancement & $7(77.8)$ & $19(33.9)$ & 0.024 \\
\hline Bone invasion & $5(55.6)$ & $7(12.5)$ & 0.006 \\
\hline Calcification & $1(11.1)$ & $6(10.7)$ & 0.972 \\
\hline \multicolumn{4}{|l|}{ Pathological findings } \\
\hline Mitotic index & $14.8 \pm 4.9$ & $3.5 \pm 3.9$ & $<0.001$ \\
\hline$<4$ & $0(0.0)$ & $33(58.9)$ & \\
\hline$\geq 8$ & $8(88.9)$ & $8(14.3)$ & \\
\hline$\geq 15$ & $7(77.8)$ & $2(3.6)$ & \\
\hline Hypercellularity & $6(66.7)$ & $48(85.7)$ & 0.172 \\
\hline Small-cell change & $4(44.4)$ & $34(60.7)$ & 0.363 \\
\hline Macronucleoli & $6(66.7)$ & $41(73.2)$ & 0.685 \\
\hline Sheeting & $6(66.7)$ & $30(53.6)$ & 0.943 \\
\hline Necrosis & $8(88.9)$ & $33(58.9)$ & 0.117 \\
\hline Ki-67 index & $20.7 \pm 13.9$ & $9.5 \pm 7.1$ & 0.010 \\
\hline \multicolumn{4}{|l|}{ Brain invasion } \\
\hline Present & $3(33.3)$ & $19(33.9)$ & 0.999 \\
\hline $\mathrm{N} / \mathrm{A}$ & $6(66.7)$ & $30(53.6)$ & \\
\hline Gross total resection & $6(66.7)$ & $49(87.5)$ & 0.124 \\
\hline Postoperative radiotherapy & $5(55.6)$ & $27(48.2)$ & 0.683 \\
\hline
\end{tabular}

Values are presented as mean \pm standard deviation or number (\%). $p$-values from the univariate logistic regression analysis. N/A : not applicable 
strategies for these patients.

In a previously published study, Kwon et al. ${ }^{27)}$ have stated that the MI was the only predictive factor for high-grade transformation in grade I meningiomas. The mean MI of patients and controls showed a significant difference $(2.0 \pm 1.1$ vs. $0.4 \pm 0.7)$, and approximately half of the patients $(42.9 \%)$ showed an MI of $3^{27)}$. In the current study as well, multivariate analysis showed the mitotic count to be the only independent factor for predicting the risk of malignant transformation in atypical meningiomas.

A number of reports have highlighted the MI as a marker for aggressiveness and a high potential for proliferation ${ }^{25,40,48)}$.
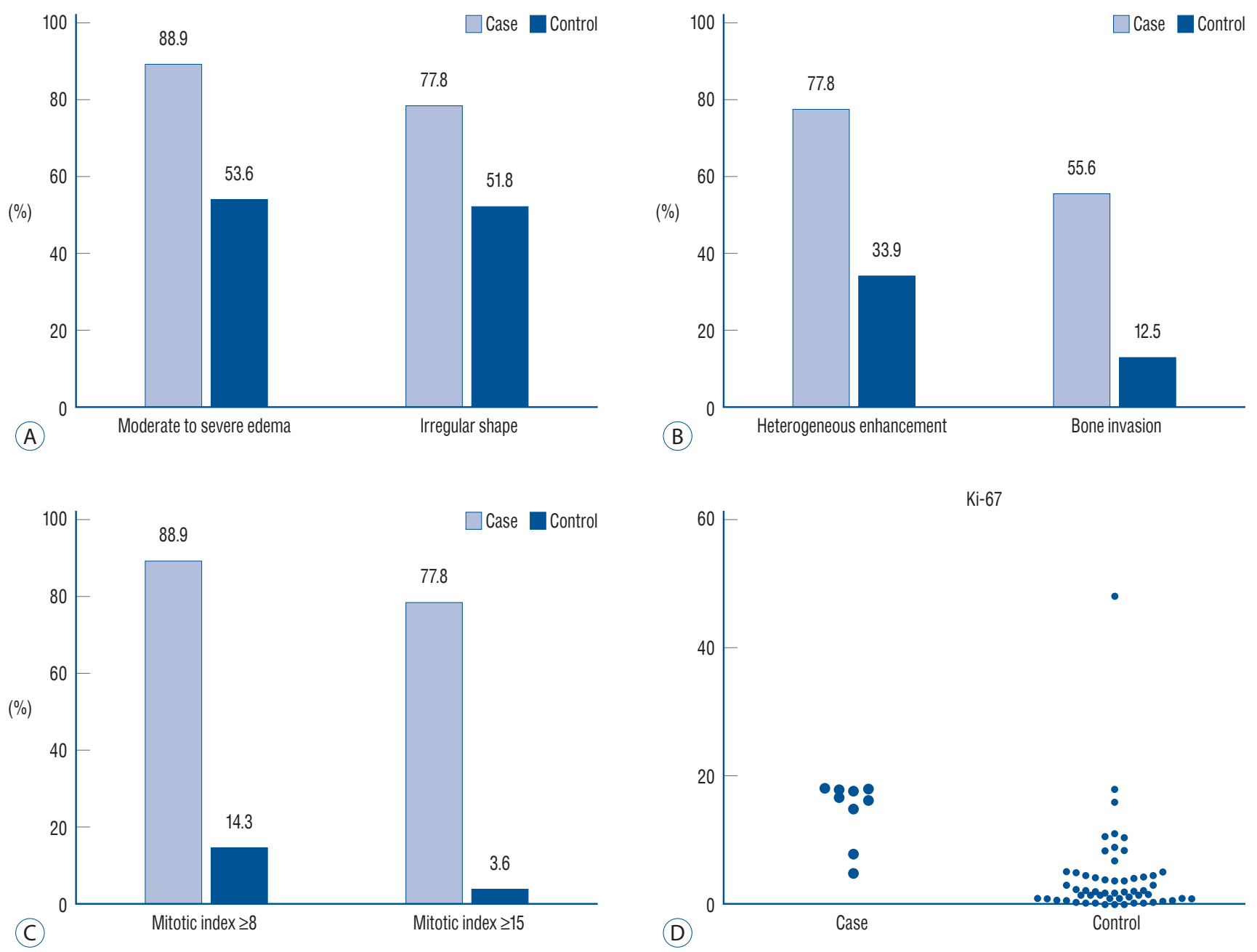

Fig. 2. Comparison of the radiological $(A$ and $B$ ) and histopathological $(C$ and $D)$ characteristics of the tumors in the study and control groups.

Table 3. Multivariate logistic regression analysis for predictors of high grade transformation

\begin{tabular}{lccc}
\hline Variable & Adjusted OR & 95\% Cl & p-value \\
\hline Moderate to severe edema & 6.573 & $0.058-743.475$ & 0.435 \\
Heterogeneous enhancement & 5.422 & $0.295-99.690$ & 0.255 \\
Bone invasion & 9.235 & $0.590-144.636$ & 0.113 \\
Mitotic index & 1.463 & $1.127-1.900$ & 0.004 \\
Ki-67 index & 1.041 & $0.793-1.159$ & 0.665 \\
\hline
\end{tabular}

OR : odds ratio, $\mathrm{Cl}$ : confidence interval 
Moreover, the current WHO grading criteria are primarily based on the number of mitosis per unit area, and atypical meningiomas are classified as tumors where the MI is between 4 and $19^{31)}$. However, despite well-defined histopathological criteria, wide spectrum of their mitotic count leads to withingrade heterogeneity in the proliferative potential of individual tumors ${ }^{2,15,40)}$. Olar et al. ${ }^{36)}$ have published data on recurrencefree survival based on the MI in their series of 84 patients with grade II meningiomas. When the patients were segregated into two groups according to their MI ( $0-4$ vs. $\geq 5)$, the groups displayed a significant difference in the recurrencefree survival (median 424 weeks vs. 204 weeks, $p<0.01$ ). The clinical significance of MI as a marker of proliferative potential was also proven in the present study. Seven of the nine patients (77.8\%) had an $\mathrm{MI} \geq 15$ in the study group, whereas more than half $(58.9 \%)$ of the patients in the control group had an MI $<4$. In a previous study by Vranic et al. ${ }^{48)}$ that included 86 patients with high-grade meningioma, the mitotic count as a continuous variable showed a strong association with recurrence/progression of the tumor (hazard ratio [HR], 1.08; 95\% CI, 1.03-1.13; $p=0.001$ ). Similarly, Lee et al. ${ }^{29)}$ have shown the significance of the mitotic count as a continuous variable ( $\mathrm{HR}, 1.24 ; 95 \% \mathrm{CI}, 1.07-1.44 ; p=0.004)$, indicating atypical meningioma as a heterogeneous group in their recurrence rate with regard to their mitotic activity. In line with previous reports, the results of this study indicate that the MI could be a helpful tool for further stratifying the risk of progression within grade II meningiomas. Interestingly, two patients (case No. 1 and 2) showed a short transformation interval (9 and 7 months, respectively), despite having relatively low MI. Both of them had at least one history of surgery for recurrence of atypical meningioma before being included in the study. It is hypothesized that this clinical characteristic may indicate more aggressiveness of tumors, although they showed relatively indolent pathological result.

However, determining the cut-off value for predicting the recurrence or progression of the meningioma is challenging. Sun et al. ${ }^{47}$ have analyzed 119 atypical meningiomas with no brain invasion and reported that those with an MI $\geq 8$ had a significantly higher rate of recurrence than those with an MI $\leq 7$ (25.0\% vs. $4.0 \%, p<0.001)$. The 5 -year rate of local control of the groups with an MI $\geq 8$ and $\mathrm{MI} \leq 7$ were $62 \%$ and $98 \%$, respectively $(p<0.001)$. Another study by Budohoski et al. ${ }^{12)}$ has reported the predictors of early progression after analyz- ing 220 atypical meningiomas and also reported $\mathrm{MI}>7$ as a significant predictor of progression (OR, 4.27; 95\% CI, 1.40$12.19 ; p=0.007)$. In line with their findings, the ROC analysis in this study revealed the highest validity for the prediction of malignant transformation at an MI of 8 . Nevertheless, this result should be interpreted cautiously because of our small sample size, and further studies are necessary.

The presence of brain invasion is also reported to be a wellknown prognostic factor for the recurrence or progression of meningioma ${ }^{9,25)}$. Moreover, in several studies, only the mitotic count and brain invasion have been reported as significant prognostic factors for recurrence ${ }^{47,48}$. However, the most critical limitation is the fact that brain invasion can only be assessed when brain tissue is included in the surgical speci$\operatorname{men}^{39)}$. In the current study, we could identify brain tissue in the pathological slides in three of nine (33.3\%) study cases and 26 of 56 (46.4\%) controls; all three patients (100\%) from the study group and 19 of the 26 patients (73.1\%) from the control group showed brain invasion, but there was no statistical significance between the two groups.

In our series, the radiological findings, which are markers for tumor aggressiveness, were not statistically significant in predicting the malignant transformation of atypical meningiomas. The study group showed a higher proportion of moderate to severe edema ( $88.9 \%$ vs. $53.6 \%$ ) and heterogeneous enhancement $(77.8 \%$ vs. $33.9 \%)$ than the control group, but the differences were not significant. Previous reports have linked the interruption of physiological barrier between the tumor and the brain parenchyma, a cerebrospinal fluid cleft and an arachnoid membrane, as a mechanism of peritumoral ede$\mathrm{ma}^{18,44)}$. After analyzing the correlation between peritumoral edema and recurrence rate, Mantle et al. ${ }^{33)}$ have demonstrated that the cortical invasiveness of the mass was the cause of the edema around the tumor, resulting in a higher rate of recurrence. In addition, in the analysis of 220 patients with meningioma by Budohoski et al. ${ }^{12)}$, the authors reported that the presence of peritumoral edema had a $92 \%$ sensitivity in predicting 24-month recurrence. They suggested that the presence of edema was highly correlated with early aggressive behavior and could be used to determine the frequency of clinical surveillance ${ }^{12}$. Correspondingly, our previous study has also shown a relative association between prominent peritumoral edema and high-grade transformation of benign meningiomas, although this association was not significant (ad- 
justed OR, 33.822; $p=0.054)^{27)}$. Future large-scale investigations through volumetric analysis are needed to better validate peritumoral edema as a predictor of malignant transformation.

There have been many reports suggesting that heterogeneous enhancement is associated with aggressive behavior of the tumor ${ }^{8,35)}$. Salah et al. ${ }^{43)}$ have compared the radiological appearance of benign and high-grade meningiomas (WHO grades II and III) and demonstrated that the heterogeneous pattern of enhancement was the most significant finding to differentiate between the two groups. Non-uniform pathological features caused by a heterogeneous distribution of proliferating cells or intratumoral necrosis may account for the heterogeneous enhancement of tumors ${ }^{14,24)}$. However, based on our results, these radiological characteristics may suggest that the tumor itself has an aggressive high-grade potential, but they were not significant predictors of malignant transformation.

In the univariate analysis, the presence of bone invasion showed a significant association with malignant transformation. It is unclear whether the changes in adjacent bone represent direct tumor invasion or secondary manifestation ${ }^{5,25)}$. However, increasing evidence suggests that osteolytic bone invasion and tumor extending into the soft tissue should be considered invasive, even when their initial pathology appears to be benign ${ }^{19,37,50)}$. In our series, the study group showed a significantly higher rate of bone invasion than observed in the control group (55.6\% vs. $12.5 \%$ ). However, it was not a significant predictor of malignant transformation.

Our results highlight the clinical implication of the mitotic count as a predictive factor of malignant transformation of atypical meningiomas. However, there are some intra- and inter-observer variabilities in quantifying the mitotic figures in small unit areas of $10 \mathrm{HPF}^{6,42)}$. In addition, the heterogeneity in the number of mitosis in different areas of the tumor might lead to difficulties and inconsistencies in assessing the grade of meningiomas ${ }^{16)}$. Bollag et al. ${ }^{10)}$ have reported the case of invasive meningioma with admixture of $20 \%$ meningothelial, $45 \%$ atypical, and $35 \%$ anaplastic subtypes. At the time of recurrence, the tumor almost entirely followed an anaplastic pattern ${ }^{10)}$. Given the wide range of morphological heterogeneity in high-grade meningiomas, they emphasized on the broad sampling of tumors with thorough histopathological evaluation.

This study has some limitations. First, it was a retrospective study conducted at a single institution, making selection bias inevitable. Second, the number of included patients was small, which can decrease the statistical power because the inclusion was limited to patients with atypical meningioma that had undergone malignant transformation. Third, since the followup period of the control group is limited, we cannot exclude the possibility of future malignant transformation.

\section{CONCLUSION}

For a more focused clinical follow-up, it is important to identify and predict patients in whom the atypical meningioma is likely to undergo malignant transformation. Our results indicate that a higher MI within grade II meningioma might add relevant information in assessing the risk of malignancy. Identifying the risk might improve decision-making during patient management and warrant attentive clinical surveillance.

\section{CONFLICTS OF INTEREST}

No potential conflict of interest relevant to this article was reported.

\section{INFORMED CONSENT}

This type of study does not require informed consent.

\section{AUTHOR CONTRIBUTIONS}

\author{
Conceptualization : JHK \\ Data curation : SJN \\ Formal analysis : SMK \\ Funding acquisition : SMK \\ Methodology : SMK \\ Writing - original draft : SMK \\ Writing - review \& editing : JHK, YHK, SHH, YHC, CJK
}




\section{ORCID}

$\begin{array}{ll}\text { Sae Min Kwon } & \text { https://orcid.org/0000-0001-9720-6037 } \\ \text { Jeong Hoon Kim } & \text { https://orcid.org/0000-0001-7385-2368 } \\ \text { Young-Hoon Kim } & \text { https://orcid.org/0000-0002-8852-6503 } \\ \text { Seok Ho Hong } & \text { https://orcid.org/0000-0003-4349-7021 } \\ \text { Young Hyun Cho } & \text { https://orcid.org/0000-0002-3274-5096 } \\ \text { Chang Jin Kim } & \text { https://orcid.org/0000-0003-2036-8294 } \\ \text { Soo Jeong Nam } & \text { https://orcid.org/0000-0001-9376-359X }\end{array}$

\section{- Acknowledgements}

This research was supported by the Bisa Research Grant of Keimyung University in 2019.

\section{- Supplementary materials}

The online-only data supplement is available with this article at https://doi.org/10.3340/jkns.2021.0114.

\section{References}

1. Adegbite $A B$, Khan MI, Paine KW, Tan LK : The recurrence of intracranial meningiomas after surgical treatment. J Neurosurg 58 : 51-56, 1983

2. Aghi MK, Carter BS, Cosgrove GR, Ojemann RG, Amin-Hanjani S, Martuza RL, et al. : Long-term recurrence rates of atypical meningiomas after gross total resection with or without postoperative adjuvant radiation. Neurosurgery 64 : 56-60; discussion 60, 2009

3. Aizer AA, Bi WL, Kandola MS, Lee EQ, Nayak L, Rinne ML, et al. : Extent of resection and overall survival for patients with atypical and malignant meningioma. Cancer 121 : 4376-4381, 2015

4. Al-Mefty O, Kadri PA, Pravdenkova S, Sawyer JR, Stangeby C, Husain M : Malignant progression in meningioma: documentation of a series and analysis of cytogenetic findings. J Neurosurg 101 : 210-218, 2004

5. Alvarez F, Roda JM, Pérez Romero M, Morales C, Sarmiento MA, Blázquez MG : Malignant and atypical meningiomas: a reappraisal of clinical, histological, and computed tomographic features. Neurosurgery 20 : 688-694, 1987

6. Ammendola S, Bariani E, Eccher A, Capitanio A, Ghimenton C, Pantanowitz $L$, et al. : The histopathological diagnosis of atypical meningioma: glass slide versus whole slide imaging for grading assessment. Virchows Arch 478 : 474-756, 2021

7. Arai H, Beppu T, Wada T, Yoshida Y, Kubo Y, Suzuki M, et al. : Pathological analyses of early recurrence and malignant transformation in meningiomas. Brain Tumor Pathol 15 : 37-40, 1998

8. Ayerbe J, Lobato RD, de la Cruz J, Alday R, Rivas JJ, Gómez PA, et al. : Risk factors predicting recurrence in patients operated on for intracranial meningioma. A multivariate analysis. Acta Neurochir (Wien) 141 : 921-932, 1999

9. Barresi V, Lionti S, Caliri S, Caffo M : Histopathological features to define atypical meningioma: what does really matter for prognosis? Brain Tumor Pathol 35 : 168-180, 2018

10. Bollag RJ, Vender JR, Sharma $S$ : Anaplastic meningioma: progression from atypical and chordoid morphotype with morphologic spectral variation at recurrence. Neuropathology 30 : 279-287, 2010

11. Brokinkel B, Spille DC, Brokinkel C, Hess K, Paulus W, Bormann E, et al. : The Simpson grading: defining the optimal threshold for gross total resection in meningioma surgery. Neurosurg Rev 44 : 1713-1720, 2021

12. Budohoski KP, Clerkin J, Millward CP, O'Halloran PJ, Waqar M, Looby S, et al. : Predictors of early progression of surgically treated atypical meningiomas. Acta Neurochir (Wien) 160 : 1813-1822, 2018

13. Claus EB, Bondy ML, Schildkraut JM, Wiemels JL, Wrensch M, Black PM : Epidemiology of intracranial meningioma. Neurosurgery 57 : 10881095; discussion 1088-1095, 2005

14. Dietemann JL, Heldt N, Burguet JL, Medjek L, Maitrot D, Wackenheim A : CT findings in malignant meningiomas. Neuroradiology 23 : 207209, 1982

15. Domingues PH, Sousa P, Otero Á, Gonçalves JM, Ruiz L, de Oliveira C, et al. : Proposal for a new risk stratification classification for meningioma based on patient age, WHO tumor grade, size, localization, and karyotype. Neuro Oncol $16: 735-747,2014$

16. Duregon $E$, Cassenti $A$, Pittaro $A$, Ventura $L$, Senetta $R$, Rudà $R$, et al. : Better see to better agree: phosphohistone $\mathrm{H} 3$ increases interobserver agreement in mitotic count for meningioma grading and imposes new specific thresholds. Neuro Oncol 17 : 663-669, 2015

17. Goldbrunner R, Minniti G, Preusser M, Jenkinson MD, Sallabanda K, Houdart $E$, et al. : EANO guidelines for the diagnosis and treatment of meningiomas. Lancet Oncol 17 : e383-e391, 2016

18. Ide $\mathrm{M}$, Jimbo $\mathrm{M}$, Kubo $\mathrm{O}$, Yamamoto $\mathrm{M}$, Imanaga $\mathrm{H}$ : Peritumoral brain edema associated with meningioma--histological study of the tumor margin and surrounding brain. Neurol Med Chir (Tokyo) 32 : 65-71, 1992

19. Ildan F, Erman T, Göçer Al, Tuna $M$, Bağdatoğlu H, Cetinalp E, et al. : Predicting the probability of meningioma recurrence in the preoperative and early postoperative period: a multivariate analysis in the midterm follow-up. Skull Base 17 : 157-171, 2007

20. Ishino S, Hashimoto N, Fushiki S, Date K, Mori T, Fujimoto M, et al. : Loss of material from chromosome arm $1 p$ during malignant progression of meningioma revealed by fluorescent in situ hybridization. Cancer 83 : 360-366, 1998

21. Jääskeläinen J, Haltia $M$, Laasonen $E$, Wahlström $T$, Valtonen $S$ : The growth rate of intracranial meningiomas and its relation to histology. An analysis of 43 patients. Surg Neurol 24 : 165-172, 1985

22. Jääskeläinen J, Haltia M, Servo A : Atypical and anaplastic meningiomas: radiology, surgery, radiotherapy, and outcome. Surg Neurol 25 : 233 242, 1986

23. Jellinger $\mathrm{K}$, Slowik $\mathrm{F}$ : Histological subtypes and prognostic problems in meningiomas. J Neurol $208:$ 279-298, 1975 
24. Kawahara Y, Nakada M, Hayashi Y, Kai Y, Hayashi Y, Uchiyama N, et al. : Prediction of high-grade meningioma by preoperative MRI assessment. J Neurooncol 108 : 147-152, 2012

25. Kim D, Niemierko A, Hwang WL, Stemmer-Rachamimov AO, Curry WT, Barker FG, et al. : Histopathological prognostic factors of recurrence following definitive therapy for atypical and malignant meningiomas. J Neurosurg 128 : 1123-1132, 2018

26. Krayenbühl N, Pravdenkova S, Al-Mefty 0 : De novo versus transformed atypical and anaplastic meningiomas: comparisons of clinical course, cytogenetics, cytokinetics, and outcome. Neurosurgery 61 : 495-503; discussion 503-504, 2007

27. Kwon SM, Kim JH, Yoo HJ, Kim YH, Hong SH, Cho YH, et al. : Predictive factors for high-grade transformation in benign meningiomas. Clin Neurol Neurosurg 195 : 105897, 2020

28. Lamszus K, Kluwe L, Matschke J, Meissner H, Laas R, Westphal M : Allelic losses at 1p, 9q, 10q, 14q, and 22q in the progression of aggressive meningiomas and undifferentiated meningeal sarcomas. Cancer Genet Cytogenet 110 : 103-110, 1999

29. Lee KD, DePowell JJ, Air EL, Dwivedi AK, Kendler A, McPherson CM : Atypical meningiomas: is postoperative radiotherapy indicated? Neurosurg Focus 35 : E15, 2013

30. Lindblom A, Ruttledge M, Collins VP, Nordenskjöld M, Dumanski JP : Chromosomal deletions in anaplastic meningiomas suggest multiple regions outside chromosome 22 as important in tumor progression. Int J Cancer 56 : 354-357, 1994

31. Louis DN, Perry A, Reifenberger G, von Deimling A, Figarella-Branger D, Cavenee WK, et al. : The 2016 World Health Organization classification of tumors of the central nervous system: a summary. Acta Neuropathol (Berl) $131: 803-820,2016$

32. Maiuri F, Mariniello G, Barbato M, Corvino S, Guadagno E, Chiariotti L, et al. : Malignant intraventricular meningioma: literature review and case report. Neurosurg Rev, 2021 [Epub ahead of print]

33. Mantle RE, Lach B, Delgado MR, Baeesa S, Bélanger G : Predicting the probability of meningioma recurrence based on the quantity of peritumoral brain edema on computerized tomography scanning. J Neurosurg $91: 375-383,1999$

34. Nakasu S, Nakasu Y, Nakajima M, Matsuda M, Handa J : Preoperative identification of meningiomas that are highly likely to recur. J Neurosurg $90:$ 455-462, 1999

35. Nanda A, Bir SC, Konar S, Maiti T, Kalakoti P, Jacobsohn JA, et al. : Outcome of resection of WHO grade II meningioma and correlation of pathological and radiological predictive factors for recurrence. J Clin Neurosci 31 : 112-121, 2016

36. Olar A, Wani KM, Sulman EP, Mansouri A, Zadeh G, Wilson CD, et al. : Mitotic index is an independent predictor of recurrence-free survival in meningioma. Brain Pathol 25 : 266-275, 2015
37. Olmsted WW, McGee TP : Prognosis in meningioma through evaluation of skull bone patterns. Radiology 123 : 375-377, 1977

38. Palma L, Celli P, Franco C, Cervoni L, Cantore G : Long-term prognosis for atypical and malignant meningiomas: a study of 71 surgical cases. J Neurosurg $86:$ 793-800, 1997

39. Perry A, Scheithauer BW, Stafford SL, Lohse CM, Wollan PC : "Malignancy" in meningiomas: a clinicopathologic study of 116 patients, with grading implications. Cancer 85 : 2046-2056, 1999

40. Perry A, Stafford SL, Scheithauer BW, Suman VJ, Lohse CM : Meningioma grading: an analysis of histologic parameters. Am J Surg Pathol $21: 1455-1465,1997$

41. Peyre M, Gauchotte G, Giry M, Froehlich S, Pallud J, Graillon T, et al. : De novo and secondary anaplastic meningiomas: a study of clinical and histomolecular prognostic factors. Neuro Oncol 20 : 1113-1121, 2018

42. Ribalta T, McCutcheon IE, Aldape KD, Bruner JM, Fuller GN : The mitosis-specific antibody anti-phosphohistone-H3 ( $\mathrm{PHH} 3$ ) facilitates rapid reliable grading of meningiomas according to WHO 2000 criteria. Am J Surg Pathol 28 : 1532-1536, 2004

43. Salah F, Tabbarah A, ALArab Y N, Asmar K, Tamim H, Makki M, et al. : Can CT and MRI features differentiate benign from malignant meningiomas? Clin Radiol 74 : 898.e15-898.e23, 2019

44. Salpietro FM, Alafaci C, Lucerna S, Iacopino DG, Todaro C, Tomasello $\mathrm{F}$ : Peritumoral edema in meningiomas: microsurgical observations of different brain tumor interfaces related to computed tomography. Neurosurgery 35 : 638-641; discussion 641-642, 1994

45. San-Miguel T, Cerdá-Nicolás M, Gil-Benso R, Callaghan RC, MuñozHidalgo L, López-Ginés C : Evolution to malignancy: a genetic stepwise study of tumor suppressor genes loss in a recurrent meningioma. Clin Neuropathol $34: 237-239,2015$

46. Simpson $D$ : The recurrence of intracranial meningiomas after surgical treatment. J Neurol Neurosurg Psychiatry 20 : 22-39, 1957

47. Sun SQ, Kim AH, Cai C, Murphy RK, DeWees T, Sylvester P, et al. : Management of atypical cranial meningiomas, part 1: predictors of recurrence and the role of adjuvant radiation after gross total resection. Neurosurgery 75 : 347-354; discussion 354-355; quiz 355, 2014

48. Vranic A, Popovic M, Cör A, Prestor B, Pizem J : Mitotic count, brain invasion, and location are independent predictors of recurrence-free survival in primary atypical and malignant meningiomas: a study of 86 patients. Neurosurgery 67 : 1124-1132, 2010

49. Wang F, Xu D, Liu Y, Lin Y, Wei Q, Gao Q, et al. : Risk factors associated with postoperative recurrence in atypical intracranial meningioma: analysis of 263 cases at a single neurosurgical centre. Acta Neurochir (Wien) $161:$ 2563-2570, 2019

50. Younis $G$, Sawaya $R$ : Intracranial osteolytic malignant meningiomas appearing as extracranial soft-tissue masses. Neurosurgery 30 : 932935, 1992 